\title{
Sex differences in reproductive fitness contribute to preferential maternal transmission of 22q11.2 deletions
}

\author{
Gregory Costain, ${ }^{1,2}$ Eva W C Chow, ${ }^{1,3}$ Candice K Silversides, ${ }^{4,5,6}$ \\ Anne S Bassett ${ }^{1,2,3,5,6}$
}

\begin{abstract}
- An additional table is published online only. To view this file please visit the journal online (http://jmg.bmj.com).

${ }^{1}$ Clinical Genetics Research Program, Centre for Addiction and Mental Health, Toronto, Ontario, Canada

${ }^{2}$ Institute of Medical Science, University of Toronto, Toronto, Ontario, Canada

${ }^{3}$ Department of Psychiatry, University of Toronto, Toronto, Ontario, Canada

${ }^{4}$ Obstetric Medicine, Mount Sinai Hospital, Toronto, Ontario, Canada

${ }^{5}$ Division of Cardiology, Department of Medicine, University Health Network Toronto, Ontario, Canada ${ }^{6}$ Toronto Congenital Cardiac Centre for Adults, Toronto General Hospital, Toronto, Ontario, Canada
\end{abstract}

\section{Correspondence to}

Dr Anne S Bassett, Centre for Addiction and Mental Health, 33 Russell Street, Room 1100, Toronto, Ontario M5S 2S1, Canada;

anne.bassett@utoronto.ca

Received 20 August 2011 Accepted 3 October 2011 Published Online First

2 November 2011

\begin{abstract}
Background 22q11.2 deletion syndrome (22q11.2DS) is the most common microdeletion syndrome in humans. In a minority of patients, the underlying 22q11.2 deletion is found to have been inherited, usually from an affected mother. Serious neuropsychiatric conditions that are commonly associated features of 22q11.2DS could disproportionately affect reproductive success in males. Methods This study compared standard measures of reproductive fitness (mean number of liveborn offspring and proportion childless) in 141 Canadian adults with 22q11.2DS (cases) and their 200 unaffected siblings (controls). Multivariate regression models were used to identify phenotypic predictors of fitness in 22q11.2DS.

Results The adults with 22q11.2DS had significantly fewer children than their siblings $(p<0.0001$, relative fitness $=0.28) ; 85.8 \%$ were childless. As expected, younger age $(p<0.0001)$, mental retardation $(p=0.0211)$, and schizophrenia $(p=0.0046)$ were significant negative predictors of reproductive fitness in 22q11.2DS; however, serious congenital heart disease was not. Female sex emerged as a significant positive predictor of fitness independent of the major neuropsychiatric phenotypes $(p=0.0082)$. Post-hoc analyses corroborated these sex differences. Notably, fitness in women with 22q11.2DS with neither mental retardation nor schizophrenia was not significantly different from that of unaffected female siblings.
\end{abstract}

Conclusions There is a strong negative selective pressure against 22q11.2 deletions. This appears to be primarily mediated by the severity of the neuropsychiatric phenotype and an independent sexual selection effect. The latter also contributes to the observed excess of transmitting mothers. These results may have implications both for the evolutionary biology of this structural rearrangement and for genetic counselling and reproductive services for adolescents and adults with 22q11.2DS.

\section{INTRODUCTION}

22q11.2 deletion syndrome (22q11.2DS) (MIM $188400 / 192430$ ) is the most common microdeletion syndrome in humans, with males and females equally affected. ${ }^{1}{ }^{2}$ There is near complete penetrance of the associated hemizygous chromosome 22q11.2 interstitial deletion for any single observable feature. ${ }^{3}$ Expression is highly variable, however, and may include various congenital and later onset manifestations such as major congenital heart disease (CHD) in 30-40\%, mental retardation (typically mild) in 30-40\%, and schizophrenia in $20-25 \% .^{245}$

22 q11.2 deletions originate as de novo events mediated by non-allelic homologous recombination, ${ }^{6}$ with low copy repeat sequences flanking the deletion and defining the common breakpoints. ${ }^{7}$ In newly diagnosed patients, only $5-10 \%$ of $22 \mathrm{q} 11.2$ deletions are found to be inherited, ${ }^{8-10}$ with a tendency for an excess of those of maternal origin. $^{9-12}$ The reasons for this are unknown, but sex differences in reproductive fitness of individuals with 22q11.2DS have been posited. ${ }^{9}{ }^{11}$

Mortality in infants and children with $22 \mathrm{q} 11.2 \mathrm{DS}$ is low in an era of modern cardiac surgical and other interventions, ${ }^{1}{ }^{2}$ and overall diminished life expectancy would be expected to have a minimal impact on the typical reproductive period. ${ }^{13}$ Thus some have proposed that $22 \mathrm{q} 11.2$ deletions may no longer be associated with the extremely reduced reproductive fitness ${ }^{14}$ that would be predicted by low rates of survival to adulthood and resulting negative selection. ${ }^{10}$ There are, however, no direct studies of fitness in 22q11.2DS

We studied reproductive fitness in 141 Canadian adults with 22q11.2DS and their 200 unaffected siblings. Based on the severity of the overall phenotype, we hypothesised that the mean number of liveborn offspring per subject with 22q11.2DS would be lower and that the proportion childless would be greater than for their siblings without 22q11.2 deletions. Furthermore, we predicted that decreased fitness within 22q11.2DS would be primarily associated with younger age and three phenotypes with independent evidence of fitness effects: $\mathrm{CHD}_{15}{ }^{15}$ mental retardation, ${ }^{17}$ and schizophrenia. ${ }^{18}{ }^{19} \mathrm{We}$ assessed sex as an independent factor but made no prediction, given that the neuropsychiatric conditions considered are known to have a disproportionate effect on the ability of men to find partners and to reproduce. ${ }^{18} 19$

\section{METHODS \\ Participants}

We considered all subjects with 22q11.2DS affiliated with a single clinic who were 18 years or older at last follow-up. As previously described, this is a well characterised cohort, with the majority ascertained for study because of CHD or a psychiatric disorder. ${ }^{13}$ All met clinical criteria for 
22q11.2DS and were confirmed to have a chromosome 22q11.2 deletion by standard methods. ${ }^{8}$ Age was recorded to the nearest 0.01 year as at 1 June 2011, at death, or at date of last contact for families lost to follow-up. As before, we classified CHD by structural complexity ${ }^{20}$ and considered only major CHD (eg, tetralogy of Fallot). ${ }^{13}$ A Diagnostic and Statistical Manual of Mental Disorders (DSM-IV) diagnosis of mild, moderate, or severe mental retardation (collectively termed 'mental retardation' in this study) was determined from functioning and IO testing results. ${ }^{21}$ Also, as before, we confirmed DSM-IV lifetime diagnoses of schizophrenia, schizoaffective disorder, or psychotic disorder not otherwise specified (collectively termed 'schizophrenia'). ${ }^{22}$ Informed consent was obtained in writing, and the study was approved by local research ethics boards.

The comparison group for this case-control study consisted of all unaffected full siblings ( $\geq 18$ years) of those with $22 q 11.2$ DS. $^{13}$ Fourteen siblings from eight families were excluded because they had not yet reached 18 years of age. Eight subjects with 22q11.2DS had no siblings, 10 had only halfsiblings, and two were adopted with no information about biological siblings. As in a previous study, ${ }^{13}$ in families where the subject with 22q11.2DS was known to have inherited a $22 q 11.2$ deletion or where parental deletion status was unknown, we included siblings only if they had negative results on testing for a 22q11.2 deletion and/or did not meet clinical screening criteria for 22q11.2DS. Extensive family history data from multiple sources and regular updates from family contacts provided information on demographics and health status, including offspring, mortality, and presence of $\mathrm{CHD}$, mental retardation, and schizophrenia, for all siblings. ${ }^{13}$

\section{Evaluations}

Reproductive fitness was estimated by the average number of liveborn offspring per subject in a specified group. ${ }^{14} 18$ The proportion of individuals childless was considered as an additional proxy for fitness. ${ }^{18}$ Data on the number of children born to study participants were collected via direct interviews and/or through collateral information from family history supplemented by genealogical records. Other pregnancy outcomes (eg, miscarriages, stillbirths) were not considered. ${ }^{18}$ We also recorded whether subjects were ever in a serious romantic relationship, which included marriage or a common-law arrangement of one year or more.

\section{Analyses}

Reproductive fitness in the 22q11.2DS group (total, and by sex) was compared with reproductive fitness in the unaffected sibling group using a Kruskal-Wallis test, a conservative non-parametric test selected to limit potential bias from a non-normal distribution. Standard statistical tests were used for other between- and within-group comparisons-that is, Student t test for other continuous variables, and Pearson's $\chi^{2}$ or Fisher's exact test for childlessness and other categorical variables. We also identified phenotypic predictors of reproductive success within each group using a multivariate linear regression model for reproductive fitness and a multivariate logistic regression model for childlessness (a dichotomous variable), and post-hoc t tests for individual regression coefficients. ${ }^{23}$ The clinically selected independent variables assessed in the models were age, sex, and $\mathrm{CHD}$, mental retardation, and schizophrenia status. Following standard procedures, a forward selection method was used to identify significant interaction terms. ${ }^{23}$ All analyses were two-tailed and performed using SAS v.9.2, ${ }^{24}$ with statistical significance defined as $\mathrm{p}<0.05$.

\section{RESULTS}

\section{Overall reproductive fitness in 22q11.2DS}

The adults with 22q11.2DS and their unaffected siblings were similar in age and sex distribution, but showed the expected differences in the clinical phenotypic characteristics of $\mathrm{CHD}$, mental retardation, and schizophrenia (table 1). There were no significant within-group or between-group differences by sex for any of the demographic or clinical variables considered (data not shown).

As predicted, the mean number of liveborn offspring in the 22 q11.2DS group was significantly lower and the proportion childless was significantly greater than for their siblings without the 22q11.2 deletion (table 2 and supplementary table 1). These differences remained significant but were somewhat less pronounced in women than in men (table 2). Overall, $16(22.5 \%)$ of the 71 women with 22q11.2DS were parents, compared with four $(5.7 \%)$ of the 70 men $(p=0.0067)$. Examining the parents and considering the number with more than two liveborn offspring, we found there were four $(20.0 \%)$ in the 22 q11.2DS group and $26(29.2 \%)$ in the unaffected sibling group ( $>0.9999)$. All four with 22q11.2DS were women, compared with $14(53.8 \%)$ of the 26 siblings ( $p=0.1297)$.

Table 1 Demographic and clinical characteristics of 141 adults with 22q11.2 deletion syndrome and their 200 unaffected siblings

\begin{tabular}{|c|c|c|c|c|c|}
\hline & \multicolumn{2}{|c|}{$\begin{array}{l}\text { 22q11.2DS } \\
(n=141)\end{array}$} & \multicolumn{2}{|c|}{$\begin{array}{l}\text { Unaffected siblings } \\
(\mathrm{n}=\mathbf{2 0 0})\end{array}$} & \multirow{2}{*}{$\begin{array}{l}\text { Analysis } \\
\text { p Value }\end{array}$} \\
\hline & Mean & (SD) & Mean & (SD) & \\
\hline \multicolumn{6}{|l|}{ Demographics } \\
\hline Mean age for those $<45$ years old and alive & 29.0 & (6.8) & 30.2 & (7.0) & $0.1734^{*}$ \\
\hline Main phenotypic groups and features & n & $(\%)$ & n & (\%) & p Value \\
\hline Proportion age $\geq 45$ years old or deceased & 33 & (23.4) & 48 & $(24.0)$ & $0.8987 \dagger$ \\
\hline Female sex & 71 & $(50.4)$ & 104 & $(52.0)$ & $0.7647 \dagger$ \\
\hline Major congenital heart disease & $60 \S$ & $(42.6)$ & 0 & $(0.0)$ & $<0.0001 \ddagger$ \\
\hline Mental retardation & 67 & (47.5) & 3 & (1.5) & $<0.0001 \neq$ \\
\hline Schizophrenia & 55 & $(39.0)$ & 2 & $(1.0)$ & $<0.0001 \ddagger$ \\
\hline Neither mental retardation nor schizophrenia & 53 & $(37.6)$ & 195 & (97.5) & $<0.0001 \neq$ \\
\hline \multicolumn{6}{|c|}{$\begin{array}{l}\text { 22q11.2DS, 22q11.2 deletion syndrome. } \\
\text { *Student } \mathrm{t} \text { test }(\mathrm{t}=1.4, \mathrm{df}=257) \text {. } \\
\text { †Pearson's } \chi^{2} \text { test }\left(\chi^{2}<0.1, \mathrm{df}=1\right) \text {. } \\
\text { fFisher's exact test. } \\
\S \mathrm{n}=48 \text { with tetralogy of Fallot (with or without pulmonary atresia), } \mathrm{n}=6 \text { with interrupted aortic arch type } \mathrm{B}, \mathrm{n}=3 \text { with pulmonary } \\
\text { atresia, } \mathrm{n}=1 \text { with truncus arteriosus, } \mathrm{n}=1 \text { with double inlet left ventricle, and } \mathrm{n}=1 \text { with ventricular septal defect and right ventricular } \\
\text { outflow tract obstruction; } \mathrm{n}=2 \text { (both women) with inoperable lesions. }\end{array}$} \\
\hline
\end{tabular}


Table 2 Reproductive fitness in a sample of adults with 22q11.2 deletion syndrome and their unaffected siblings

\begin{tabular}{|c|c|c|c|c|c|c|c|c|c|c|c|c|c|c|c|}
\hline & \multicolumn{5}{|c|}{$22 q 11.2$ deletion syndrome } & \multicolumn{5}{|c|}{ Unaffected siblings } & \multicolumn{5}{|c|}{ Analyses } \\
\hline & \multirow{2}{*}{$\begin{array}{l}\text { Total } \\
\text { n }\end{array}$} & \multicolumn{2}{|c|}{$\begin{array}{l}\text { Childless } \\
\text { subjects }\end{array}$} & \multicolumn{2}{|c|}{$\begin{array}{l}\text { Live born } \\
\text { offspring }\end{array}$} & \multirow{2}{*}{$\begin{array}{l}\text { Total } \\
\mathrm{n}\end{array}$} & \multicolumn{2}{|c|}{$\begin{array}{l}\text { Childless } \\
\text { subjects }\end{array}$} & \multicolumn{2}{|c|}{$\begin{array}{l}\text { Live born } \\
\text { offspring }\end{array}$} & \multicolumn{2}{|c|}{ Childlessness* } & \multicolumn{2}{|c|}{$\begin{array}{l}\text { Live born } \\
\text { offspring } \dagger\end{array}$} & \multirow[t]{2}{*}{$\begin{array}{l}\text { Relative } \\
\text { fitness } \neq\end{array}$} \\
\hline & & $\bar{n}$ & $(\%)$ & $\operatorname{Max}$ & Mean & & $\bar{n}$ & $(\%)$ & Max & Mean & $\overline{\chi^{2}}$ & $\overline{p \text { Value }}$ & $\mathrm{H}$ & $\overline{\text { p Value }}$ & \\
\hline All subjects & 141 & 121 & $(85.8)$ & 4 & 0.2624 & 200 & 111 & (55.5) & 5 & 0.9250 & 34.9 & $<0.0001$ & 35.4 & $<0.0001$ & 0.2837 \\
\hline Males & 70 & 66 & (94.3) & 2 & 0.1000 & 96 & 56 & $(58.3)$ & 4 & 0.8438 & 26.9 & $<0.0001$ & 26.4 & $<0.0001$ & 0.1185 \\
\hline Females & 71 & 55 & $(77.5)$ & 4 & 0.4225 & 104 & 55 & $(52.9)$ & 5 & 1.0000 & 10.9 & 0.0010 & 11.7 & 0.0006 & 0.4225 \\
\hline \multicolumn{16}{|c|}{ Subgroup with completed fertility } \\
\hline Males & 16 & 13 & (81.2) & 2 & 0.3125 & 27 & 10 & $(37.0)$ & 4 & 1.4444 & $\S$ & 0.0103 & 8.4 & 0.0037 & 0.2164 \\
\hline Females & 17 & 11 & (64.7) & 4 & 0.9412 & 21 & 5 & $(23.8)$ & 5 & 1.6190 & $\S$ & 0.0201 & 3.4 & 0.0671 & 0.5814 \\
\hline \multicolumn{16}{|c|}{ Subgroup with neither mental retardation nor schizophrenia } \\
\hline All subjects & 53 & 37 & (69.8) & 4 & 0.5472 & 195 & 108 & (55.4) & 5 & 0.9333 & 3.6 & 0.0588 & 4.3 & 0.0377 & 0.5863 \\
\hline Males & 27 & 23 & (85.2) & 2 & 0.2593 & 95 & 56 & (58.9) & 4 & 0.8421 & $\S$ & 0.0123 & 6.3 & 0.0118 & 0.3079 \\
\hline Females & 26 & 14 & (53.8) & 4 & 0.8462 & 100 & 52 & $(52.0)$ & 5 & 1.0200 & $<0.1$ & 0.8666 & 0.2 & 0.6229 & 0.8296 \\
\hline
\end{tabular}

*Pearson's $\chi^{2}$ test.

tKruskal-Wallis test.

łln the absence of age differences, defined as a simple ratio of mean numbers of liveborn offspring in 22q11.2DS compared to the corresponding unaffected sibling mean; the latter therefore has a relative fitness set at 1.0 .

$\S$ Fisher's exact test.

\section{Within-group analyses of reproductive fitness}

In the 22q11.2DS group, the multivariate linear regression model for reproductive fitness was highly significant $(F(5,135)=10.7$, $\mathrm{p}<0.0001$; adjusted $\mathrm{R}^{2}=0.26$ ). Consistent with our hypothesis, younger age $(t=5.1, d f=131, p<0.0001)$, mental retardation $(\mathrm{t}=2.3, \mathrm{df}=1, \mathrm{p}=0.0211)$, and schizophrenia $(\mathrm{t}=2.9, \mathrm{df}=1$, $\mathrm{p}=0.0046)$ were significant negative predictors of fitness. Contrary to our prediction, however, CHD status was noncontributory ( $\mathrm{t}=0.2, \mathrm{df}=1, \mathrm{p}=0.8693$ ). Notably, female sex was a significant independent positive predictor of fitness $(t=2.7$, $\mathrm{df}=1, \mathrm{p}=0.0082$ ). There were no significant interaction terms. The multivariate logistic regression model for childlessness (likelihood ratio test: $\chi^{2}=42.4, \mathrm{df}=5, \mathrm{p}<0.0001$ ) yielded comparable results (data not shown). In the unaffected sibling group, while age showed similar results as in the 22q11.2DS group, female sex was not a significant predictor of either fitness measure (data not shown).

\section{Post-hoc analyses}

The observed between-group differences in reproductive fitness cannot be attributed to any differences in mean age between the adults with 22q11.2DS and their unaffected siblings. Crosssectional comparisons between age matched groups may not, however, distinguish between decreased fitness and delayed reproduction. ${ }^{18}$ We therefore repeated our analyses using subgroups with completed fertility-that is, those individuals likely to be through the reproductive period ( $\geq 45$ years or deceased). ${ }^{18} 25$ Comparable differences to those in the overall sample were present between the adults with 22q11.2DS and their unaffected siblings, and between the men and women with 22q11.2DS (table 2). We note that the fitness of unaffected siblings with completed fertility was similar to the Canadian average reported for the 5 year period from 2004 to 2008 (1.6 children per woman). ${ }^{26}$

Second, to further examine sex effects on reproductive fitness in 22q11.2DS, we undertook post-hoc exploratory analyses involving the subsets of adults without major neuropsychiatric phenotypes - that is, those with neither mental retardation nor schizophrenia. The results showed that reproductive fitness in women with 22q11.2DS in this subgroup was comparable to that of unaffected female siblings, but fitness in men with 22q11.2DS was still significantly less than in the male siblings (table 2). A multivariate linear regression model for reproductive fitness in this 22q11.2DS subgroup, with sex, age, and CHD as independent variables, was highly significant $(\mathrm{F}(3,49)=19.8$, $\mathrm{p}<0.0001$; adjusted $\left.\mathrm{R}^{2}=0.52\right)$. As before, age $(t=7.0, \mathrm{df}=1$, $p<0.0001)$ and female sex $(t=3.1, d f=1, p=0.0035)$ were significant predictors of fitness and there was no appreciable impact of CHD $(t=1.1, d f=1, p=0.2882)$. The corresponding logistic regression model for childlessness (likelihood ratio test: $\chi^{2}=27.0$, $\mathrm{df}=3, \mathrm{p}<0.0001)$ showed similar results (data not shown).

\section{Timing of reproduction}

There was no significant between-group difference in mean age at first child (22q11.2DS: 26.0 years, siblings: 26.3 years; $t=0.2$, $\mathrm{df}=102, \mathrm{p}=0.8155)$. There was, however, a non-significant trend towards an older mean age at first child among the men with 22 11.2DS (31.3 years) compared with the men in the unaffected sibling group ( 27.0 years; $\mathrm{t}=1.6, \mathrm{df}=38, \mathrm{p}=0.1122$ ). The men with 22q11.2DS were on average significantly older than the women when they had their first child (males: 31.3 years, females: 24.7 years; $t=3.8, d f=18, p=0.0014$ ).

\section{Transmission of 22q11.2 deletions to offspring}

Consistent with the expected transmission pattern, ${ }^{1} 19$ (51.4\%) of the 37 total offspring born to individuals with 22 q11.2DS are known, or suspected based on clinical features, to have inherited the 22q11.2 deletion. The sex of the parent with 22q11.2DS had no appreciable impact on the rate of transmission of the deletion to offspring (16 mothers with 15 of 30 offspring affected and four fathers with four of seven offspring affected). Of the seven offspring born to men with 22q11.2DS, four sons inherited the $22 q 11.2$ deletion and three daughters did not $(p=0.0286)$. This was in contrast to the nine sons and six daughters who did, and the six sons and nine daughters who did not, inherit the deletion from their mothers with 22q11.2DS ( $p=0.4661)$.

\section{Serious romantic relationships and mating success}

A comparable prevalence of serious romantic relationships in both adults with 22q11.2DS and their unaffected siblings would suggest that impaired fertility may underlie the observed lower reproductive fitness in the 22q11.2DS group. However, significantly fewer-25 (17.7\%; 20 females) of the 141 adults with 22q11.2DS-had ever had a serious romantic relationship, 
compared with $114(57.0 \%$; 62 females) of the 200 unaffected siblings $\left(\chi^{2}=52.8, \mathrm{df}=1, \mathrm{p}<0.0001\right)$. Similar significant betweengroup differences were observed with males or females only (data not shown). Sex differences in fitness within 22q11.2DS were also paralleled by similar differences in rates of romantic partnerships, with fewer in males (five of 70) than in females (20 of 71; $\mathrm{p}=0.0016$ ). Notably, of the childless adults with 22 q11.2DS, only one male and five females had a history of such relationships.

\section{DISCUSSION}

In a contemporary sample of adults with 22q11.2DS, we found that overall relatively few had children and that reproductive fitness was significantly lower than in their unaffected siblings. Notably, across all analyses there was a prominent independent effect of sex on fitness in 22q11.2DS. The results suggest for the first time that a central contributor to a previously observed excess of maternal transmission of $22 q 11.2$ deletions may be the disproportionately reduced reproductive fitness of men with this deletion. Interestingly, there appears to be a similar tendency for de novo 22q11.2 deletions to originate preferentially on the maternal chromosome. 82728 This is likely to be a distinct phenomenon mediated by a separate mechanism. ${ }^{8}$

As predicted, younger age, mental retardation, and schizophrenia were significant negative predictors of reproductive fitness in 22q11.2DS. The effect of neuropsychiatric conditions was primarily observed in the females in this sample, as there were overall only four fathers with 22q11.2DS, but we note that these four men had neither mental retardation nor schizophrenia. Contrary to our initial hypothesis, however, major CHD had no appreciable impact on fitness in the 141 adults studied. Several previous reports of parents found to have $22 q 11.2$ deletions after transmitting the deletion to offspring were remarkable for a relative paucity of individuals with $\mathrm{CHD}^{9-12}$ This suggested the possibility that CHD could substantially reduce fitness, by lessened mating ${ }^{15}$ and/or increased mortality, ${ }^{16}$ for example. While there may certainly be some effect of serious $\mathrm{CHD}$ on mating success and reproductive choices in 22q11.2DS, our results did not support $\mathrm{CHD}$ as a major contributor to fitness in this sample. Our results may also reflect the contemporary expectation of survival of individuals with major CHD to reproductive age and beyond. ${ }^{29}$

The results show a rather surprising extent of the sex differences in reproductive fitness in 22q11.2DS. These appeared to be independent of the major neuropsychiatric phenotypes mental retardation and schizophrenia, which are relatively common in $22 \mathrm{q} 11.2 \mathrm{DS}$. Indeed, in the 22q11.2DS group, women with neither of these conditions showed reproductive fitness that approached that of unaffected sisters of probands with 22 q11.2DS, while men with neither condition had about $30 \%$ of the offspring of the unaffected male siblings (table 2). There are several possible explanations for these findings. First, fertility in 22 q11.2DS could be preferentially impaired in men. ${ }^{9}$ There is no evidence for this in the literature ${ }^{12} 30$ nor in our data, but fertility has not yet been directly studied. Second, there could be increased mortality in early adulthood (age $<45$ years) in men with 22q11.2DS. ${ }^{11}$ The only study of longevity after childhood in $22 q 11.2 D S$ reported on just 12 adult deaths. ${ }^{13}$ Third, there may be an ascertainment bias, with mothers more often available to be tested for the 22q11.2 deletion. Fourth, there may be sex differences in mating success. For example, delayed emotional/behavioural maturity in $22 \mathrm{q} 11.2 \mathrm{DS}^{31}$ may have a disproportionate impact on men with respect to the ability to establish or sustain intimate relationships. Consistent with this possibility are our findings of delayed reproduction in those men who did father children and a significantly lower rate of romantic partnerships in men. A relative increase in female fitness, perhaps driven by a subgroup of women, could also contribute. Borderline intellectual deficits, impaired judgement, and/or increased vulnerability to exploitation have been posited to explain similar observations in other disorders. ${ }^{18} 3233$ The sex differences in reproductive fitness in 22q11.2DS clearly warrant further study.

An unexpected finding was an apparent sex bias involving preferential paternal transmission of the 22q11.2 deletion to sons. This was based on few observations, however (offspring of only four fathers). We therefore examined the literature for studies reporting on comparable data (reviewed in part elsewhere ${ }^{11} 12$ ). Including the current study, 33 men with 22q11.2DS fathered significantly more affected sons $(n=34)$ than affected daughters $(n=17 ; p=0.0120)$; there was no significant sex bias in transmission of the $22 \mathrm{q} 11.2$ deletion to offspring of mothers with 22q11.2DS (data not shown). ${ }^{10-12}{ }^{34-36}$ Possible explanations for this observation include a parent-of-origin effect that has a disproportionate impact on male or female offspring, a differential impact of sex chromosomes on the viability of sperm carrying a 22q11.2 deletion, or an ascertainment or reporting bias. Further epidemiological and molecular studies would be needed to confirm these intriguing observations and elucidate their associated biology.

\section{Advantages and limitations}

This is the first study of reproductive fitness in 22q11.2DS, and the first to compare directly potential contributory phenotypes in adults with 22q11.2DS. We considered a large, well characterised cohort of individuals with 22q11.2DS somewhat enriched for major CHD, mental retardation, and schizophrenia, which provided sufficient power to assess the impact of each of these features on fitness and to identify differences of large effect in pertinent subgroups. Previous reports of adults with 22q11.2DS with children were enriched for transmitting parents (ie, individuals ascertained after the birth of an affected child). ${ }^{9-12}$ For example, in the largest previous study that provided detail on family structure, $26(81.2 \%)$ of the 32 total offspring of 20 parents with 22q11.2DS were affected (excluding $\mathrm{n}=2$ offspring who died before deletion studies). ${ }^{10}$ The approximately $50 \%$ recurrence risk observed in offspring in our study suggests we may have results that reflect a more representative portrait of parents with 22q11.2 deletions and their offspring. Use of unaffected siblings as a comparison group allowed us to control for the known effects of family structure and culture on fitness. $^{14} 1825$

On the other hand, our study has several limitations. We have relied on the assumption that the vast majority of liveborn offspring will survive to reproductive age and beyond. ${ }^{12}$ We did not account for assortative mating, a phenomenon, ubiquitous in nature, ${ }^{37}$ that may have an impact on the severity of the phenotype in offspring, and ultimately their survival and fitness. ${ }^{38}$ We have also assumed that fertility is unaffected in $22 \mathrm{q} 11.2 \mathrm{DS} .^{30}$ Reproductive fitness is the measure relevant to genetics and the issue of selection; impaired fertility may contribute to fitness in $22 \mathrm{q} 11.2 \mathrm{DS},{ }^{14}{ }^{25}$ an area deserving separate study. Pregnancy loss and health issues also deserve separate study. We acknowledge that our results are based on a relatively small number of adults with 22q11.2DS who have become parents. In particular, the small number of fathers with 22q11.2DS in this sample precluded a rigorous analysis of determinants of fitness specific to males with 22q11.2DS and 
suggests caution in generalising overall phenotype effects (eg, of neuropsychiatric illness) to this subgroup. Our results are nonetheless highly consistent overall with previous reports of transmitting parents, ${ }^{9-12}$ and our main findings were robust to multiple subgroup and other analyses. Reproductive fitness in the unaffected sibling group was not rigorously compared to population based norms (eg, those derived from local census figures). However, most potential biases, such as less frequent updates on family size for siblings compared with probands or social selection ${ }^{39}$ (voluntary limiting of family size), would lead to lower estimates of total fitness in unaffected siblings and thereby strengthen our main findings.

\section{Biological implications}

The results suggest that despite improved paediatric survival, there remains a strong negative selective pressure against 22q11.2 deletions. However, the advances in medical management of associated features may be catalysing a real-time shift in the evolutionary biology paradigm for this structural rearrangement from natural selection to sexual selection. ${ }^{40}$ In addition to the high rate of recombination at the 22q11.2DS locus, the existence of a subset of women in whom the 22q11.2 deletion is selectively neutral may be an increasingly important contributor to the persistence of $22 q 11.2$ deletions. Indeed, although the true prevalence of $22 \mathrm{q} 11.2$ deletions in the general population remains poorly characterised, these novel reproductive fitness estimates in combination with improved medical and surgical management of associated features suggest there may be a modest increase in prevalence of children and adults with 22q11.2DS in the short term.

There remains significant uncertainty regarding the future prevalence of $22 \mathrm{q} 11.2$ deletions. Fitness in 22q11.2DS and the relative contribution of different traits will continue to change over time, and longitudinal studies are needed. ${ }^{14} 25$ Future improvements in treatment could ameliorate the neuropsychiatric components of the phenotype that significantly affect fitness. Also, to our knowledge, and consistent with low rates reported elsewhere for comparably aged cohorts, ${ }^{41} 42$ there were no selective terminations on the basis of known or suspected 22q11.2 deletions in this sample. Expanded prenatal screening could dramatically affect both the overall incidence of $22 q 11.2$ deletions and the observed fitness in carriers. For example, adoption of genome-wide microarray technologies as a standard practice in prenatal screening could have a major impact on the rate of selective termination in pregnancies carrying $22 \mathrm{q} 11.2$ deletions, the majority of which would be spontaneous mutations. Currently, the possibility of selective termination mainly exists for the majority with major anomalies detectable on fetal ultrasound and those at $50 \%$ risk of transmission. ${ }^{41}{ }^{42}$ For the latter, this would require that the parent already be diagnosed with 22q11.2DS, have received adequate genetic counselling, and that the salient information be recalled and acted upon. However, 22q11.2DS remains underdiagnosed in adults, and traditional genetic counselling models may or may not be effective in individuals with intellectual disabilities and/or major psychiatric illness. ${ }^{43} 44$

Pathogenic copy number variation (CNV) and its relationship to reproductive fitness, disease prevalence, natural selection, and human evolution is of growing interest in genetics. ${ }^{3} 45$ There remains a lack of data on fitness associated with other genomic disorders ${ }^{46}$ that are increasingly compatible with survival to reproductive age. These results for 22q11.2DS suggest caution in interpreting sex differences in parent-of-origin of CNV (eg, as evidence for or against imprinting effects ${ }^{47}$ ) when inheritance status is unknown, because observed prevalence could be confounded by fitness effects. ${ }^{48}$ Also, other highly penetrant $\mathrm{CNV}$ s associated with neuropsychiatric illness may continue to be under strong negative selection despite improved viability. ${ }^{3}$ As for 22q11.2 deletions, known and hypothesised mechanisms of recurrence would account for the persistence of these structural mutations in the face of the reduced fitness associated with their full expression. ${ }^{6}{ }^{46}$ On the other hand, increasing rates of transmission are likely, particularly in the current generation of adolescents and adults.

\section{Clinical implications}

These results emphasise the need for genetic counselling for all individuals with 22q11.2DS of reproductive age, regardless of sex and associated features. ${ }^{1}$ Although women with 22q11.2DS and comparatively mild neuropsychiatric phenotypes (borderline to average intellect and no psychotic illness) - a subgroup with modest impairment in reproductive fitness-are estimated to comprise approximately $25 \%$ of the total population with 22 q11.2 deletions, they accounted for just 22 of the $37(59.5 \%)$ offspring reported in this study. Early intervention and support will be essential: a third of the mothers with 22q11.2DS in this study had at least one child by age 23 years, and half had at least one child by age 25 years. A multidisciplinary team-based approach to reinforce key aspects of genetic counselling and sexual health may be most successful at addressing the challenges in effective provision of information to individuals with a variety of learning styles and disabilities. ${ }^{43} 4449$ Improvements in clinical management of adults, as for those in children, promise to have future effects on reproductive fitness deserving of future study. The interplay between the forces of evolutionary biology and contemporary clinical management will continue to shape the nature of reproduction in 22q11.2DS.

Funding This work was supported by Canadian Institutes of Health Research grants (MOP-97800 and MOP-89066), a Vanier Canada Graduate Scholarship (GC), and a Canada Research Chair in Schizophrenia Genetics and Genomic Disorders (ASB). The funding organisation played no role in the design of the study, the collection or interpretation of data, the preparation of the manuscript, or the decision to publish.

\section{Competing interests None.}

Ethics approval Centre for Addiction and Mental Health Research Ethics Board (Toronto, Ontario).

Contributors GC designed the study, assisted with data collection, analysed and interpreted the data, and drafted and revised the manuscript; ASB designed the study, assisted with data collection, monitored data analysis and interpretation, and drafted and revised the manuscript; EWCC and CKS assisted with the collection and interpretation of data, and critically revised the manuscript; GC and ASB are the guarantors. All authors have approved the final manuscript. Many other research assistants, graduate students, and genetic counsellors assisted with data collection

Provenance and peer review Not commissioned; externally peer reviewed.

Data sharing statement Pertinent raw data are in supplementary table 1.

\section{REFERENCES}

1. Bassett AS, McDonald-McGinn DM, Devriendt K, Digilio MC, Goldenberg P, Habel A Marino B, Oskarsdottir S, Philip N, Sullivan K, Swillen A, Vorstman J; International 22q11.2 Deletion Syndrome Consortium. Practical guidelines for managing patients with 22q11.2 deletion syndrome. J Pediatr 2011;159:332-9.e1.

2. McDonald-McGinn DM, Sullivan KE. Chromosome $22 q 11.2$ deletion syndrome (DiGeorge syndrome/velocardiofacial syndrome). Medicine (Baltimore) 2011;90:1-18

3. Bassett AS, Scherer SW, Brzustowicz LM. Copy number variations in schizophrenia: critical review and new perspectives on concepts of genetics and disease. Am J Psychiatry 2010;167:899-914

4. Bassett AS, Chow EW, Husted J, Weksberg R, Caluseriu O, Webb GD, Gatzoulis MA. Clinical features of 78 adults with 22q11 Deletion Syndrome. Am J Med Genet A 2005; 138:307-13.

5. Fung WL, McEvilly R, Fong J, Silversides C, Chow E, Bassett A. Elevated prevalence of generalized anxiety disorder in adults with 22q11.2 deletion syndrome. Am J Psychiatry 2010;167:998. 
6. Stankiewicz $\mathbf{P}$, Lupski JR. Genome architecture, rearrangements and genomic disorders. Trends Genet 2002;18:74-82.

7. Edelmann L, Pandita RK, Morrow BE. Low-copy repeats mediate the common 3-Mb deletion in patients with velo-cardio-facial syndrome. Am J Hum Genet 1999:64:1076-86.

8. Bassett AS, Marshall CR, Lionel AC, Chow EW, Scherer SW. Copy number variations and risk for schizophrenia in 22q11.2 deletion syndrome. Hum Mol Genet 2008; 17:4045-53

9. Digilio MC, Angioni A, De Santis M, Lombardo A, Giannotti A, Dallapiccola B, Marino B. Spectrum of clinical variability in familial deletion 22q11.2: from full manifestation to extremely mild clinical anomalies. Clin Genet 2003;63:308-13.

10. McDonald-McGinn DM, Tonnesen MK, Laufer-Cahana A, Finucane B, Driscoll DA, Emanuel BS, Zackai EH. Phenotype of the 22q11.2 deletion in individuals identified through an affected relative: cast a wide FlSHing net! Genet Med 2001:3:23-9.

11. Cohen E, Chow EW, Weksberg R, Bassett AS. Phenotype of adults with the 22q11 deletion syndrome: A review. Am J Med Genet 1999;86:359-65.

12. Leana-Cox J, Pangkanon S, Eanet KR, Curtin MS, Wulfsberg EA. Familial DiGeorge/ velocardiofacial syndrome with deletions of chromosome area 22q11.2: report of five families with a review of the literature. Am J Med Genet 1996;65:309-16.

13. Bassett AS, Chow EW, Husted J, Hodgkinson KA, Oechslin E, Harris L, Silversides C. Premature death in adults with 22q11.2 deletion syndrome. J Med Genet 2009;46:324-30.

14. Orr HA. Fitness and its role in evolutionary genetics. Nat Rev Genet 2009:10:531-9.

5. Reid GJ, Siu SC, McCrindle BW, Irvine MJ, Webb GD. Sexual behavior and reproductive concerns among adolescents and young adults with congenital heart disease. Int J Cardiol 2008;125:332-8.

16. Siu SC, Sermer M, Colman JM, Alvarez AN, Mercier LA, Morton BC, Kells CM, Bergin ML, Kiess MC, Marcotte F, Taylor DA, Gordon EP, Spears JC, Tam JW, Amankwah KS, Smallhorn JF, Farine D, Sorensen S; Cardiac Disease in Pregnancy (CARPREG) Investigators. Prospective multicenter study of pregnancy outcomes in women with heart disease. Circulation 2001:104:515-21.

17. Weiber I, Berglund J, Tengland PA, Eklund M. Children born to women with intellectual disabilities - 5-year incidence in a Swedish county. J Intellect Disabil Res 2011:55:1078-85.

18. Bassett AS, Bury A, Hodgkinson KA, Honer WG. Reproductive fitness in familial schizophrenia. Schizophr Res 1996;21:151-60.

19. Bundy H, Stahl D, MacCabe JH. A systematic review and meta-analysis of the fertility of patients with schizophrenia and their unaffected relatives. Acta Psychiatr Scand 2011:123:98-106

20. Billett J, Cowie MR, Gatzoulis MA, Vonder Muhll IF, Majeed A. Comorbidity, healthcare utilisation and process of care measures in patients with congenital heart disease in the UK: cross-sectional, population-based study with case-control analysis. Heart 2008;94:1194-9.

21. Chow EW, Watson M, Young DA, Bassett AS. Neurocognitive profile in 22q11 deletion syndrome and schizophrenia. Schizophr Res 2006;87:270-8.

22. Bassett AS, Chow EW, AbdelMalik P, Gheorghiu M, Husted J, Weksberg R. The schizophrenia phenotype in 22q11 deletion syndrome. Am J Psychiatry 2003;160:1580-6.

23. Vittinghoff E. Regression Methods in Biostatistics: Linear, Logistic, Survival, and Repeated Measures Models. New York: Springer, 2005.

24. SAS Institute. SAS/STAT Software: Changes and Enhancements Through Release 6.12. Cary, NC: SAS Institute Inc., 1997.

25. Stearns SC, Byars SG, Govindaraju DR, Ewbank D. Measuring selection in contemporary human populations. Nat Rev Genet 2010;11:611-22.

26. Statistics Canada. Births and Total Fertility Rate, by Province and Territory (Table). Canadian Statistics, 2011. http://www40.statcan.ca/l01/cst01/hlth85b-eng.htm (accessed 15 Aug 2011).

27. Thomas NS, Durkie M, Potts G, Sandford R, Van Zyl B, Youings S, Dennis NR, Jacobs PA. Parental and chromosomal origins of microdeletion and duplication syndromes involving 7q11.23, 15q11-q13 and 22q11. Eur J Hum Genet 2006;14:831-7.
28. Torres-Juan L, Rosell J, Sánchez-de-la-Torre M, Fibla J, Heine-Suñer D. Analysis of meiotic recombination in 22q11.2, a region that frequently undergoes deletions and duplications. BMC Med Genet 2007;8:14.

29. Hickey EJ, Veldtman G, Bradley TJ, Gengsakul A, Manlhiot C, Williams WG, Webb GD, McCrindle BW. Late risk of outcomes for adults with repaired tetralogy of Fallot from an inception cohort spanning four decades. Eur J Cardiothorac Surg 2009;35:156-64

30. Kapadia RK, Bassett AS. Recognizing a common genetic syndrome: 22q11.2 deletion syndrome. CMAJ 2008:178:391-3.

31. Baker KD, Skuse DH. Adolescents and young adults with 22q11 deletion syndrome: psychopathology in an at-risk group. Br J Psychiatry 2005;186:115-20.

32. Fryns JP. The female and the fragile $X$. A study of 144 obligate female carriers. Am J Med Genet 1986;23:157-69.

33. Loesch DZ, Hay DA. Clinical features and reproductive patterns in fragile $X$ female heterozygotes. J Med Genet 1988;25:407-14.

34. Adeyinka A, Stockero KJ, Flynn HC, Lorentz CP, Ketterling RP, Jalal SM. Familial 22q11.2 deletions in DiGeorge/velocardiofacial syndrome are predominantly smaller than the commonly observed 3Mb. Genet Med 2004;6:517-20.

35. Campbell JM, Knutsen AP, Becker BA. A 39-year-old father is diagnosed in adulthood as having partial DiGeorge anomaly with a combined $\mathrm{T}$ - and B-cell immunodeficiency after diagnosis of the condition in his daughter. Ann Allergy Asthma Immunol 2008;100:620-1.

36. Yamamoto T, Sameshima K, Sekido K, Aida N, Matsumoto N, Naritomi K, Kurosawa K. Trigonocephaly in a boy with paternally inherited deletion 22q11.2 syndrome. Am J Med Genet A 2006;140:1302-4.

37. Blachford A, Agrawal AF. Assortative mating for fitness and the evolution of recombination. Evolution 2006;60:1337-43.

38. Swillen A, Devriendt K, Legius E, Eyskens B, Dumoulin M, Gewillig M, Fryns JP. Intelligence and psychosocial adjustment in velocardiofacial syndrome: a study of 37 children and adolescents with VCFS. J Med Genet 1997;34:453-8.

39. Yokoyama S. Social selection and evolution of human diseases. Am J Phys Anthropol 1983;62:61-6.

40. Darwin C. The Descent of Man, and Selection in Relation to Sex. London: J. Murray, 1871.

41. Bretelle F, Beyer L, Pellissier MC, Missirian C, Sigaudy S, Gamerre M, D’Ercole C, Philip N. Prenatal and postnatal diagnosis of 22q11.2 deletion syndrome. Eur J Med Genet 2010:53:367-70.

42. McDonald-McGinn DM, Zackai EH. Genetic counseling for the 22q11.2 deletion Dev Disabil Res Rev 2008:14:69-74.

43. Farwig K, Harmon AG, Fontana KM, Mervis CB, Morris CA. Genetic counseling of adults with Williams syndrome: a first study. Am J Med Genet C Semin Med Genet 2010;154C:307-15.

44. Finucane B. Genetic counseling for women with intellectual disabilities. In: LeRoy BS, Veach PM, Bartels DM, eds. Genetic Counseling Practice: Advanced Concepts and Skills. Hoboken, NJ: Wiley-Blackwell, 2010.

45. Lupski JR. New mutations and intellectual function. Nat Genet 2010;42:1036-8

46. Lupski JR. Genomic disorders ten years on. Genome Med 2009;1:42.

47. Ingason A, Kirov G, Giegling I, Hansen T, Isles AR, Jakobsen KD, Kristinsson KT, le Roux L, Gustafsson O, Craddock N, Möller HJ, McQuillin A, Muglia P, Cichon S, Rietschel M, Ophoff RA, Djurovic $S$, Andreassen OA, Pietiläinen OP, Peltonen L, Dempster E, Collier DA, St Clair D, Rasmussen HB, Glenthøj BY, Kiemeney LA, Franke B, Tosato S, Bonetto C, Saemundsen E, Hreidarsson SJ, Nöthen MM, Gurling H, O'Donovan MC, Owen MJ, Sigurdsson E, Petursson H, Stefansson H, Rujescu D, Stefansson K, Werge T. Maternally derived microduplications at 15q11-q13: implication of imprinted genes in psychotic illness. Am J Psychiatry 2011:168:408-17.

48. Bassett AS. Parental origin, DNA structure, and the schizophrenia spectrum. Am J Psychiatry 2011:168:350-3

49. Taylor MR, Edwards JG, Ku L. Lost in transition: challenges in the expanding field of adult genetics. Am J Med Genet C Semin Med Genet 2006;142C:294-303. 